\title{
Aerosol indirect effects in complex orography areas: a numerical study over the Great Alpine Region
}

\author{
Anna Napoli ${ }^{1,2}$, Fabien Desbiolles ${ }^{3,4}$, Antonio Parodi ${ }^{1}$, and Claudia Pasquero ${ }^{3,5}$ \\ ${ }^{1}$ CIMA Research Foundation, Savona (Italy) \\ ${ }^{2}$ Università degli studi di Genova, Genova (Italy) \\ ${ }^{3}$ Università degli studi di Milano-Bicocca, Milano (Italy) \\ ${ }^{4}$ Osservatorio Geofisico Sperimentale, Trieste (Italy) \\ ${ }^{5}$ ISAC-CNR, Torino (Italy)
}

Correspondence: anna.napoli@cimafoundation.org

\begin{abstract}
Aerosols play a crucial role in climate through different feedback mechanisms, affecting radiation, clouds and air column stability. This study focuses on the altitude-dependence of the cloud mediated indirect effects of aerosols in the Great Alpine Region (GAR), an area characterised by high pollution levels from anthropic activities in the Po Valley and a complex orography with the highest mountains in Europe. Using a regional atmospheric model, 5-years long convective-permitting sensitivity experiments have been run with different surface aerosol fluxes. The results show that seasonal mean cloud cover, temperature, and precipitations are affected by the aerosol concentrations in the air column, and that the response to pollution is both elevation and season dependent. The overall cloud cover increase with aerosol levels leads to either surface cooling or warming depending on the surface albedo (snow covered or not). Furthermore, different types of clouds have a different sensitivity to aerosols: while the lifetime of low pressure system clouds and orographic clouds is generally increased at high levels of aerosols, convective clouds (typical of the summer season) can actually decrease at high levels of pollution, due to the reduction of strong updrafts.
\end{abstract}

\section{Introduction}

Aerosols affect both directly and indirectly the Earth's radiative budget and climate. As a direct effect, aerosols interact with radiation either through scattering or absorption (Haywood and Shine, 1995). The scattering of solar radiation by aerosol particles typically results in a cooling of the ground surface, while absorption of solar radiation determines local heating of the atmosphere. Moreover, as an indirect effect, in the lower atmosphere aerosols alter the microphysical and radiative properties of clouds acting as cloud condensation nuclei (CCN) and ice nuclei (IN) upon which cloud droplets and ice crystals form. Thus they can influence cloud optical properties, cloud cover, cloud lifetime, and precipitations (Albrecht, 1989; Ramanathan et al., 2001; Rosenfeld et al., 2008). Furthermore, the strong absorption of solar radiation by dark aerosols, such as black carbon, can lead to changes in cloud cover and liquid water content by heating the cloud and the environment within which the cloud forms; this is called the semi-direct effect (Hansen et al., 1997), that may have a significant warming impact on climate by 'burning off' low clouds that scatter solar radiation back to space, but have little impact on outgoing longwave radiation. Thus in the 
atmosphere, there is a mixture of scattering and absorbing aerosols, and their net effect on Earth's energy budget is dependent on surface and cloud characteristics.

In the middle of Europe, the Great Alpine Region (GAR) is characterized by its peculiar geographical shape and by complex orography, that are a meteorological trap for atmospheric pollutants emitted in the surrounding lowlands (Schroeder et al., 2014). Depending on orographic and meteorological conditions, pollutants emitted in the densely populated GAR spread in the region and lead to very high concentration of pollutants, with a strong gradient between low and high elevations (Sandrini et al., 2014).

The rate of warming observed over avere anche the last decades is elevation-dependent (Pepin et al., 2015), possibly also due to aerosols (Rangwala et al., 2010), which vary with altitude (in concentration and type) and affect the local sensitivity to large scale changes (Stjern et al., 2020). Aerosol effects could also extend to precipitation (Rosenfeld et al., 2008): the radiative effects of aerosols on clouds mostly act to suppress precipitation, because they decrease the amount of solar radiation that reaches the surface, increasing regional atmospheric stability (Zhang et al., 2020). Aerosols also have important microphysical effects on precipitation (Tao et al., 2012; Fiori et al., 2014): incresed Cloud Condensation Nuclei (CCN) slow the conversion of cloud droplets into raindrops (Thompson and Eidhammer, 2014). This effect has been shown to generally decrease precipitations (Ochoa et al., 2015), but several and sometime contrasting differences have been described in the literature, mainly depending on precipitation rate and environmental conditions (Qian et al., 2009; Alizadeh-Choobari and Gharaylou, 2017; Alizadeh-Choobari, 2018; Li et al., 2011).

While direct effects of aerosols on the climate system are in general understood and quantified, the quantification of indirect and semi-direct forcing by aerosols is especially complex (Penner et al., 2001). Currently, they are considered one of the most uncertain forcing in climate (Zhang et al., 2016). Although a number of studies on the local effect of pollutants has been published (e.g. Pavlidis et al., 2020), information about the climatological effects on the meteorological conditions of aerosols in complex orography areas at convective-permitting scale is lacking. In order to develop a better understanding of the climatic role that aerosols play, in this paper we focus our attention to the indirect effects of aerosols only, using the Weather Research and Forecasting Model.

\section{Methods}

To study the climatological indirect effects of aerosols in complex orography area, we use the Weather Research and Forecasting (WRF) Model (version 3.9.1.1). Two 5-years long simulations have been run with initial and boundary conditions provided by the Earth System Model EC-Earth on a 25 Km horizontal grid for the period (1979-1983) (Davini et al., 2017).

The study area is the Great Alpine Region, which is represented on two grafted domains shown in Fig. 1: the larger one, with a grid step of $12 \mathrm{Km}$, ranging from about $41^{\circ} \mathrm{N}$ to $51^{\circ} \mathrm{N}$ latitude and from $0^{\circ} \mathrm{E}$ to $23^{\circ} \mathrm{E}$ longitude, and a more internal one, with a grid step of $4 \mathrm{Km}$, from about $43^{\circ} \mathrm{N}$ to $49^{\circ} \mathrm{N}$ latitude and from $3.5^{\circ} \mathrm{E}$ to $19.5^{\circ} \mathrm{E}$ longitude. The outer domain includes a convection parameterization, necessary to account for the vertical motions not explicitly represented at the $12 \mathrm{Km}$ resolution that characterize the summer climate in the area under analysis. In the inner domain, convection is explicitly resolved. 


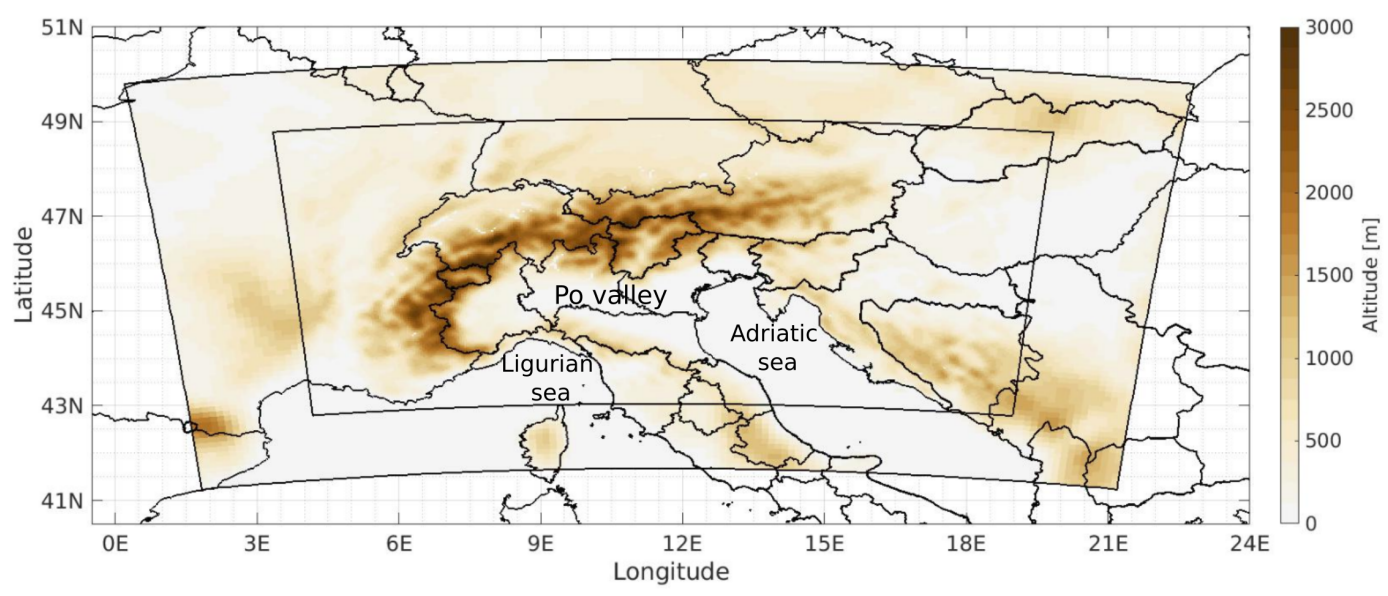

Figure 1. Topography in the two domains used for the 5-long years runs: bigger domain $12 \mathrm{Km}$ and inner domain $4 \mathrm{Km}$ of resolution. The three geographical areas Ligurian Sea, Adriatic Sea and Po Valley are labelled in the figure.

The simulations have been run with the two-way nesting approach: computations are first performed for mother domain and the boundary values of the daughter domain are replaced with mother domain values. This approach is reciprocal and simultaneous with feedbacks.

The Planetary Boundary Layer (PBL) is parametrized with the Yonsei University Scheme (Hong et al., 2006). The Shortwave and Longwave option used is the RRTMG (Iacono et al., 2008). The outer domain includes the Tiedtke Scheme (Tiedtke, 1989), covection parametrization necessary to account for the vertical motions not explicitly represented at the $12 \mathrm{Km}$ resolution that characterize the summer climate in the area under analysis. As microphysics scheme the Thompson Aerosol Aware has been used (Thompson and Eidhammer, 2014): this microphysics parametrisation has an explicit nucleation of water droplets (naCCN) and activation of ice particles (naIN) by aerosols.

Two different simulations are run, differing in the aerosol load only: in the POLLUTED experiment the mean aerosol concentration in the atmospheric boundary layer is on average about one order of magnitude larger than in the PRISTINE simulation in the lowlands, while similar concentrations are found over the mountains (see Supplementary Material, SM, section S3, Fig. $\mathrm{S} 10)$. The way this has been obtained is explained in the following. Initial vertical profiles of aerosols are provided at each location in the domain. The Thompson aerosol aware microphysics scheme then computes a fake surface aerosol emission flux from these profiles (see Fig. S9 in SM). The number concentrations of both water-friendly and ice-friendly aerosols are updated at every time step and at any grid box taking into account advection, diffusion, and tendencies induced by the aerosol-cloud interactions. A zero-gradient lateral boundary condition (no flux) is applied, and the constant fake aerosol emission flux at the surface provides the aerosol source, which is uniform in space and very low in the PRISTINE simulation and varies in the POLLUTED simulations by more than two orders of magnitude as function of surface elevation (see Fig. S9 in SM). The parameter values that define those configurations in the aerosol aware microphysics routine are provided in Section S3 of Supplementary Material. The simulations have been configured so that the aerosols of the Thompson's Aerosol Aware microphysics scheme 
don't interact with short-wave radiation (aer_opt=0), allowing us to focus on the indirect effects of aerosols only.

Indirect effects of aerosols include their influence on the radiation budget and on hydrology through their impact on cloud microphysical processes. For this reason the main variables analyzed in this work are temperature at two meters from the surface, cloud fraction and precipitation.

We define a cloud event at a given position and at a given time all cases in which there is at least one vertical level with cloud fraction equal or larger than 0.5. The number of cloud events for each pixel over a given period of time is then simply the count of cloud events during the considered time period. We verified that the precise threshold of cloud fraction chosen to define cloud events doesn't significantly impact the results. Note that in principle this metric equally weights shallow and deep clouds. However, convective clouds at times can cover a relatively small surface area and might thus not be detected by this method, which requires a cloud cover of at least $8 \mathrm{Km}^{2}$. For this reason, to analyze the occurrence of convective events we used the daily maximum upward velocity in the low to mid troposphere (i.e. at pressures higher than $400 \mathrm{hPa}$ ).

The statistical significance of the results has been assessed using the one-tail Student's t-test at the 95\% confidence level: for temperature and precipitation the Student's t-test has been performed over the hourly datasets, while for cloud events the test has been done over the annual time series of the mean seasonal number of cloud events.

\section{Results}

Aerosol concentrations are particularly large in the Planetary Boundary Layer (PBL), as the surface input of aerosols is efficiently redistributed by turbulent mixing within the whole layer, and lower aloft. The constant surface emissions in the simulations lead to PBL concentrations that are anti-correlated with PBL height: they are particularly large during winter months, when the PBL in the region is relatively shallow and pollutants are trapped near the surface (the mean winter PBL height at mid-day averaged over the whole domain is $500 \pm 100 \mathrm{~m}$, Fig. S6a in SM), and smaller during summer months, when the lower static stability of the atmosphere favors rising thermals and generates a thick PBL (mean summer PBL height at noon over the entire domain is $1300 \pm 500 \mathrm{~m}$, Fig. S6b in SM). For this reason, in the following we present results for winter (DJF) and summer (JJA) seasons separately. Considering that in our simulations aerosol input depends on elevation only, and not on surface type, high injection levels are provided over the low altitude continental areas as well as over the sea. In the POLLUTED simulation, this leads to a high aerosol concentration over the Ligurian and Adriatic seas, which is not particularly relevant for understanding the effects of urbanization and of anthropic activities. In the following, we thus present results for land points only. Figures including marine areas are shown and briefly discussed in the Supplementary Material.

The difference in the seasonal mean number of cloud events between POLLUTED and PRISTINE simulations is shown in Fig. $2 \mathrm{c}$ and d. Larger aerosol concentrations are associated with more clouds. This response is related to the well known fact that droplets nucleate over cloud condensation nuclei $(\mathrm{CCN})$ and that a larger number of cloud droplets inhibits their growth to the size where they precipitate, leading to longer cloud lifetime (Albrecht, 1989; Christensen et al., 2020). However, the change in the number of cloud events is both dependent on topography and on the season. Over continental areas, the cloud 

events are present in the Po Valley, and the increase of cloud cover is limited to high elevation areas and over the sea.

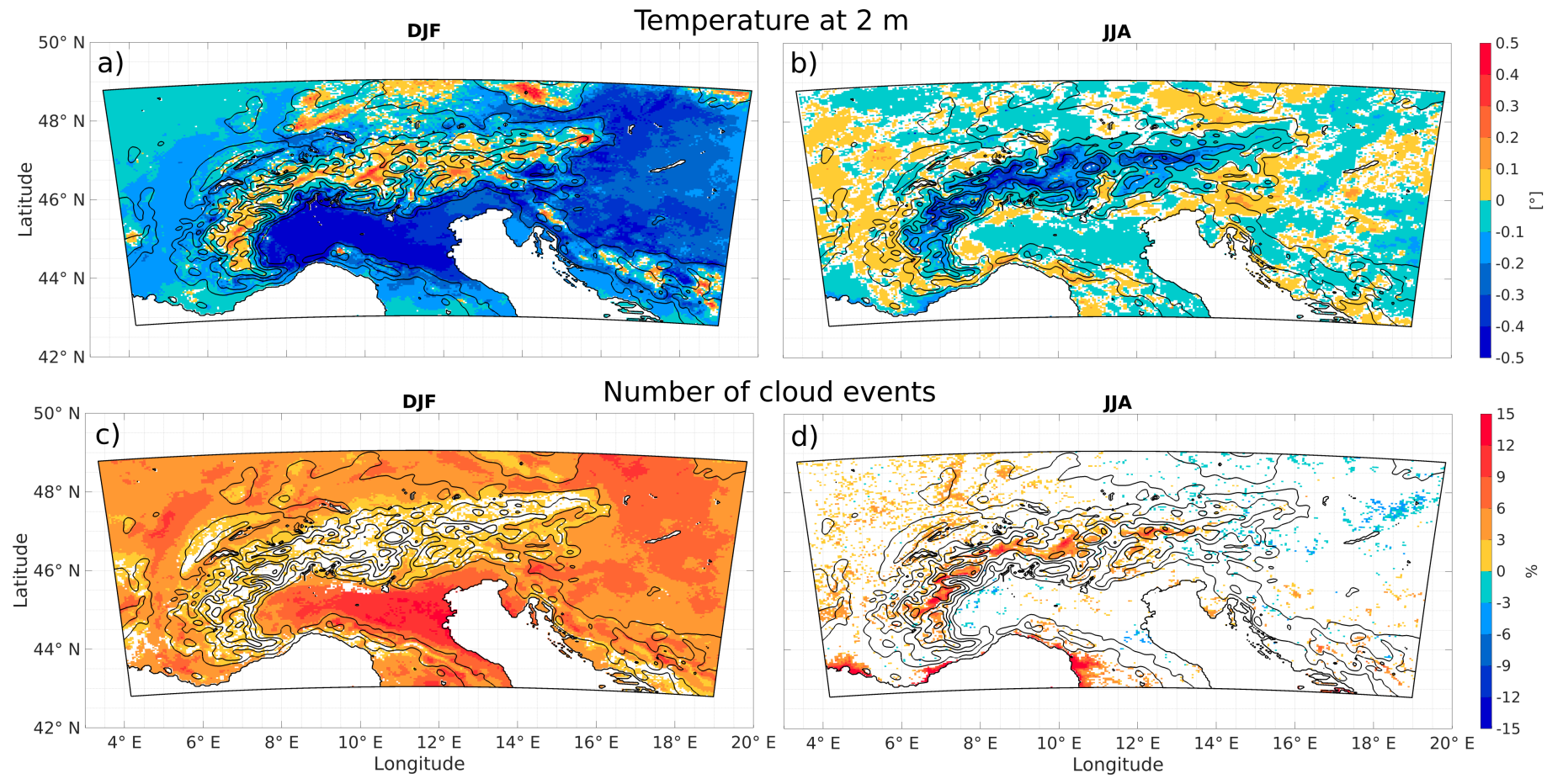

Figure 2. Seasonal mean difference in $2 \mathrm{~m}$ temperature in Winter (a) and Summer (b). Seasonal relative variation of number of cloud events in DJF (c) and in JJA (d). Coloured pixels represent points that are significant at the $95 \%$ confidence level. Altitude isolines are shown every $500 \mathrm{~m}$.

We now turn our attention to the difference in seasonal mean temperature at two meters above the ground. Figure $2 \mathrm{a}$ and $\mathrm{b}$ indicates that temperature is generally lower in the POLLUTED run compared to the PRISTINE case, especially in winters. However, a major feature emerges: in winters, over the mountains temperatures are actually higher in the POLLUTED run than in the PRISTINE one. Furthermore, lowlands are much colder in POLLUTED than in PRISTINE during winters, while during summers the differences in the lowlands are minor and of contrasting signs. Overall, the POLLUTED-PRISTINE temperature difference increases with surface elevation during winters, and decreases with surface elevation during summers.

The spatial pattern of the temperature anomaly is consistent with the difference in cloud coverage: cloud scattering decreases shortwave radiation from the sun reaching the ground, resulting in an overall surface cooling. We indeed verified that the seasonal mean shortwave radiation at the ground is always smaller in POLLUTED compared to PRISTINE. However, it remains to be clarified why a non significant change in cloud cover during winters at high elevations is associated with a temperature increase in POLLUTED, and to explain the origin of the spatial heterogeneity of the cloud cover response, which appears to be related to orography and to land-sea contrasts. For this reason, we analyze the diurnal cycle of the differences in 
cloud events and in near surface temperature at different altitudes. The differences of mean hourly temperature and of mean cloud events averaged over ranges of altitude for land points only are shown in Fig. 3.

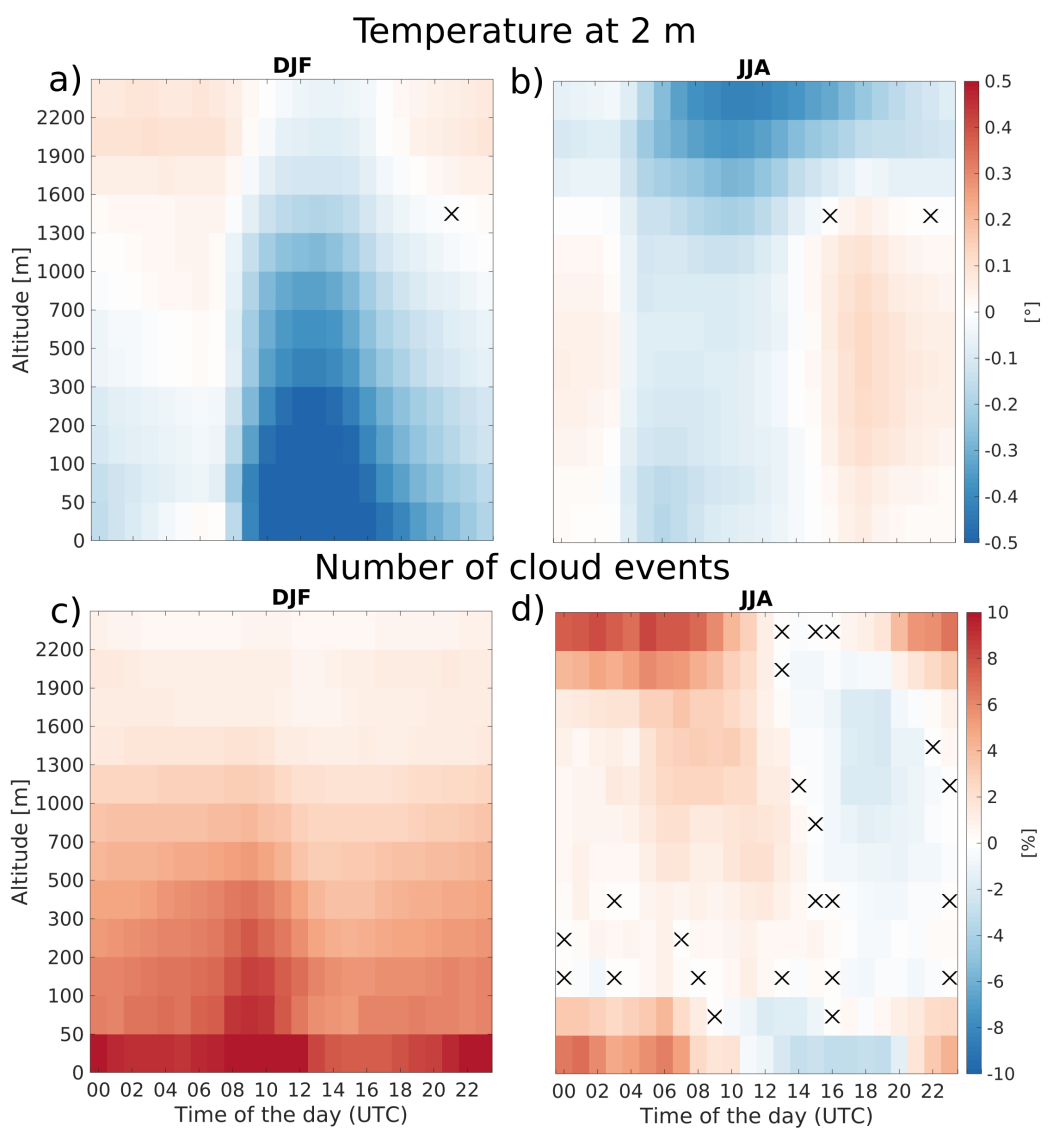

Figure 3. Daily cycle of the difference of the mean hourly temperature at $2 \mathrm{~m}$ in DJF (a) and in JJA (b). Daily cycle of the relative variation of the mean hourly number of cloud events in Winter (c) and in Summer (d). Crosses represent points that are not significant at the 95\% confidence level.

During winters, we note the presence of a relatively strong diurnal cycle in near surface temperature differences between POLLUTED and PRISTINE, which has different characteristics at different elevations (Fig. 3a). The increase in cloud cover has a strong elevation gradient, with cloud event number being $10 \%$ larger in POLLUTED than in PRISTINE over land close to sea-level, and only $1 \%$ larger over mountain areas above $2000 \mathrm{~m}$ (Fig. 3c). This first result is related to the fact that aerosol emissions strongly depend on elevation in the POLLUTED experiment, and that the stratification of the lower atmosphere prevents a significant transport of pollutants at high elevations, that remain relatively aerosol-free, with aerosol concentrations just slightly larger than in the PRISTINE case. The larger amount of clouds reduces shortwave radiation reaching the ground and near surface temperature during the daylight hours (see Fig. 3a), and it also reduces outgoing longwave radiation, allowing for the warming observed at high elevation during night hours. At low elevations the effect on shortwave radiation dominates, 
resulting in a strong reduction of daily averaged near surface temperature, while at high elevations the effect on longwave radiation dominates, resulting in a weak increase of daily averaged near surface temperature (see Fig. 2a). We'll get back to this difference in the discussion section.

During summers the daily cycle of the temperature variation (Fig. 3b) has a different behaviour compared to winter: in lowlands there is a weak negative anomaly in the first part of the day, and a weak positive anomaly starting from late afternoon, resulting in a daily mean temperature difference between POLLUTED and PRISTINE runs close to zero (see Fig. 2d), while at high elevations the anomaly is negative throughout the day, with largest values during daytime. Cloud events, rather than being increased throughout the day as in winter, are typically increased during the night and the first hours of the day, and are generally suppressed in the afternoons (see Fig. 3d), resulting in a relatively small daily mean response. This suggests that there is a reduction in the number of convective events, which are particularly frequent in late afternoons. To explore this aspects, we show in Fig. 4 the relative difference in the number of strong updrafts (vertical velocity larger than $3.5 \mathrm{~m} / \mathrm{s}$ ) between POLLUTED and PRISTINE as function of elevation. The figure shows a wide range of responses, consistent with the fact that convection is a highly intermittent process and that the interannual variability of convective storms at a specific location is large. Still, it can be seen that while the averaged updraft occurrence in the two simulations is similar at low elevations, at higher altitudes POLLUTED has less convective events than PRISTINE. The updraft velocities are also reduced in presence of many aerosols (Fig. S12 in SM).

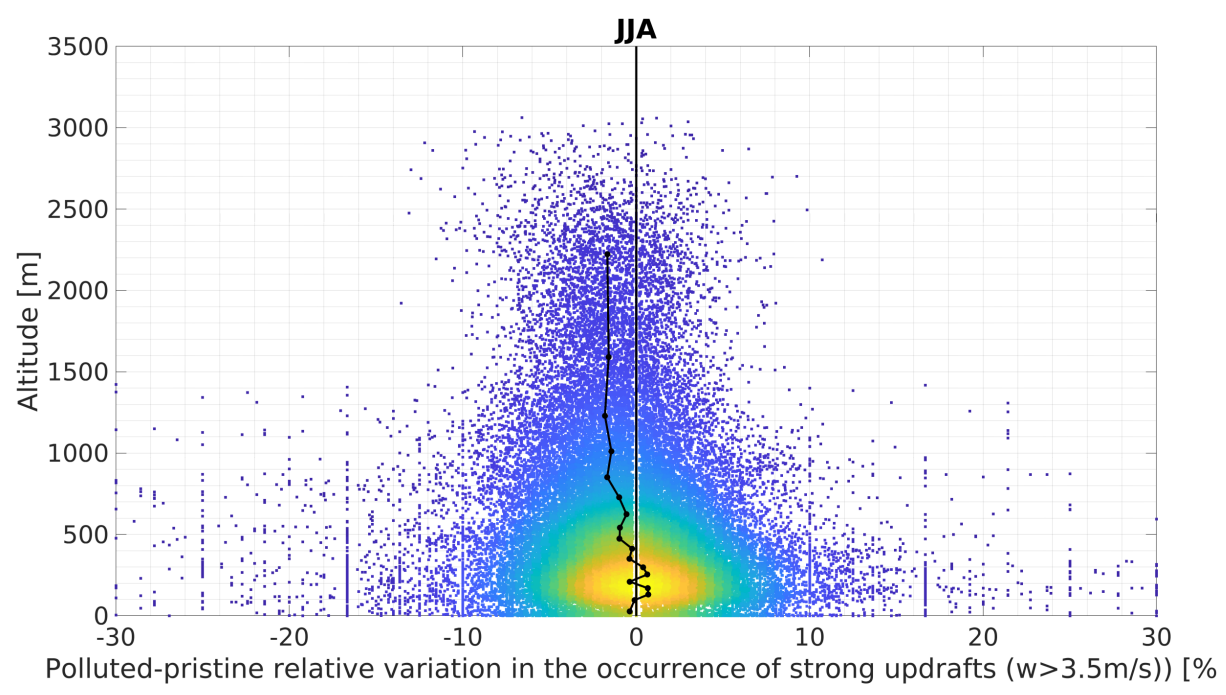

Figure 4. Relative variation of the number of events with at least $3.5 \mathrm{~m} / \mathrm{s}$ vertical velocity in function of elevation in JJA. Vertical velocity analysis has been done dividing the data in 18 classes based on station altitude, where the class limits are chosen so that each class has the same number of stations. The mean of each class is calculated and plotted with black dots.

Finally, we show in Fig. 5 the precipitation response, as function of surface elevation, which indicates a general drying. During winters, aerosol load weakly affects precipitation at sea level, then the relative variation of rainfall increases with 
https://doi.org/10.5194/acp-2021-921

Preprint. Discussion started: 15 November 2021

(c) Author(s) 2021. CC BY 4.0 License.

(c) (i)

elevation until about $1000 \mathrm{~m}$ asl where seasonal mean precipitation is reduced by about $7 \%$ in the POLLUTED run compared to PRISTINE, and at higher elevations the difference between the two runs decreases again.

During summers, the relative variation of precipitation is nearly monotonic with surface elevation, and the POLLUTED run is on average about $20 \%$ drier than the PRISTINE simulation above $2000 \mathrm{~m}$ asl.

The results presented in this section clearly indicate that the climatic response to aerosols, through their indirect effect, is complex, dependent on topography, and different in different seasons.
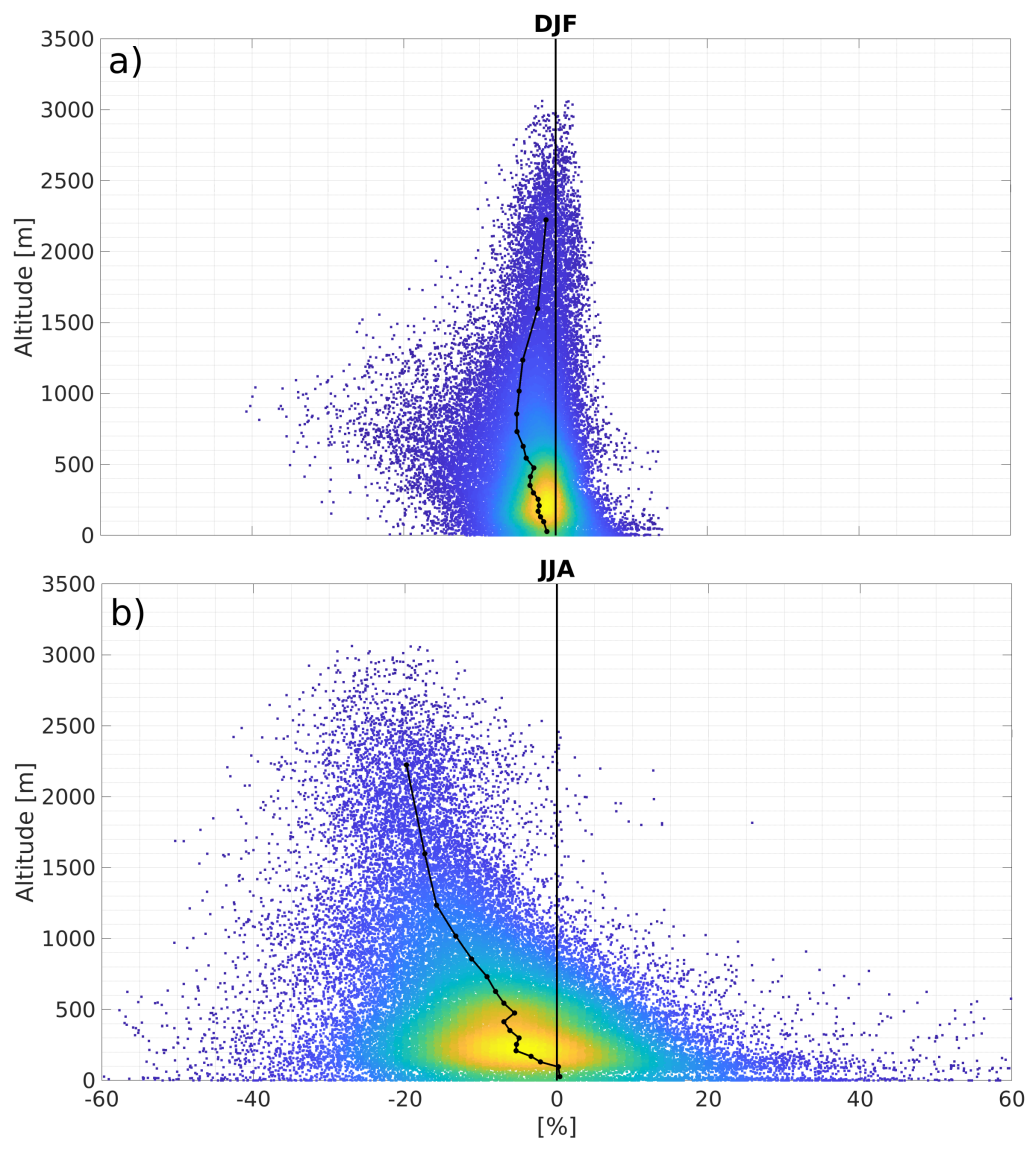

Figure 5. Relative variation of the mean seasonal precipitation in function of elevation in DJF (a) and in JJA (b). Precipitation analysis has been done dividing the data in 18 classes based on station altitude, where the class limits are chosen so that each class has the same number of stations. The mean of each class is calculated and plotted with black dots. 


\section{Discussion and conclusions}

In the previous section it was shown that the indirect effect of aerosols can lead to either warming or cooling at the surface.

The response depends on surface elevation, season, and type of surface (continental or marine). Here we discuss the physical processes that are responsible for this complex response, which has been summarized in Figure 6 for land areas.

(a)

WINTER TIME (DJ F)

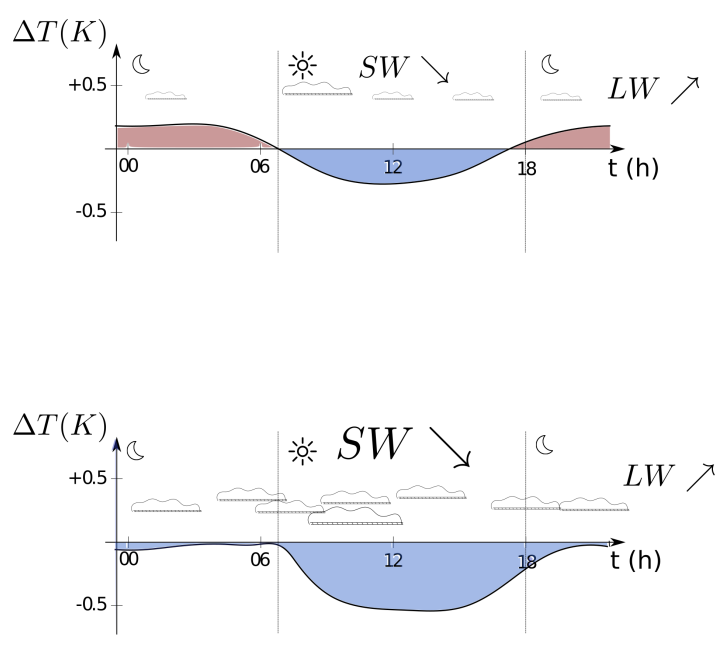

Ground Elevation

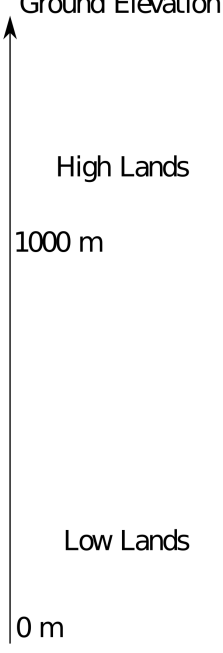

(b)

SUMMER TIME (JJA)
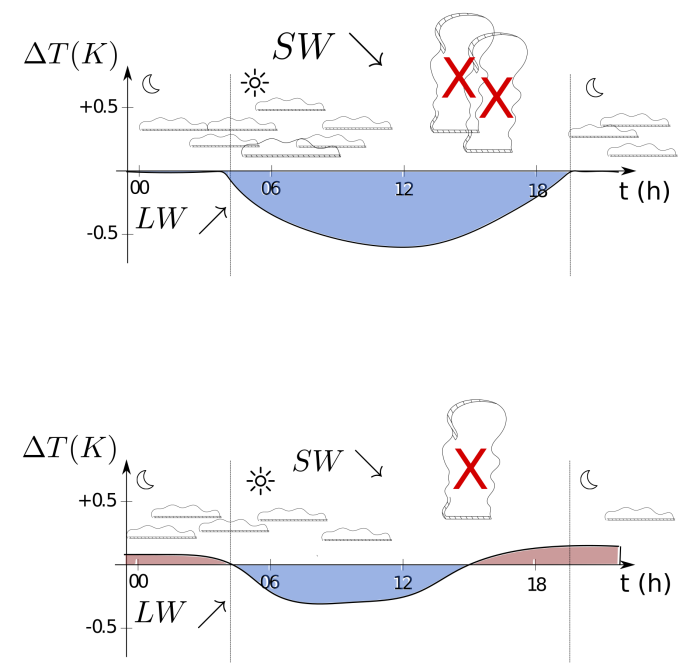

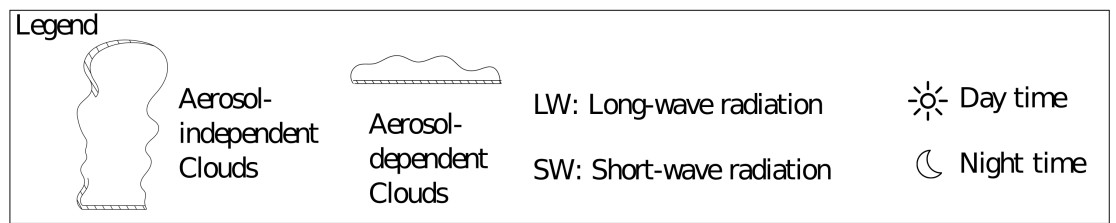

Figure 6. Concluding sketch representing the anomaly features in a POLLUTED environment in lowlands and highlands for (a) winter time (DJF) and (b) summer time (JJA). The time is in UTC.

During winters, aerosols are concentrated in lowlands, as the shallow PBL traps them near the surface. They increase the number of cloud droplets, resulting in longer lived clouds which affect both net shortwave and longwave radiation at the surface. Net shortwave radiation depends on surface albedo, being smaller over the mountains where snow cover reflects a large fraction of solar radiation, and larger over the darker flatlands. The effect of the increased cloud cover during winter is thus dominated by the reduced net incoming shortwave radiation at the surface in lowlands, while it is dominated by the reduced net outgoing longwave radiation over the mountains. Near surface temperature are reduced in presence of higher aerosol concentration during daytime in both cases, but with much larger anomalies at low elevations than at high elevations, 
where indeed the aerosol load is smaller than in the valley. The reduced daytime soil temperature persists over night at low elevations, preventing the air temperature anomaly from becoming positive during night. At high altitude, however, the daytime reduction is very small and does not last over the night, when the weakly increased cloud cover limits the infrared energy loss and leads to warmer temperatures. The longer lifetime of clouds associated with a larger number of CCN delays the onset of precipitation. While this does not really affect winter rainfall over flatlands, it leads to reduced precipitation where orographic clouds form (see Fig. 5), i.e. at medium elevations, especially on the upwind slopes (see Fig. S11 in SM).

The summer dynamics is very different from what has been described so far. Surface warming by insolation leads to a thick PBL and, consequently, relatively high concentrations of aerosols even at high elevations (see Fig. S6b and S10b in SM). It also favors the development of convective storms, that are characterized by thick clouds that rapidly precipitate. Convective cloud evolution is nearly independent of aerosols, as the growth phase of cloud droplets is very rapid, and characterized by large supersaturation values, that lead to big falling particles in less than an hour, regardless of the number of initiating CCN. For those reasons, we call them Aerosol Independent Clouds (AIC), to distinguish them from the Aerosol Dependent Clouds (ADC) linked to synoptic scale disturbances and low level clouds. During summer, both types of clouds can be present, with the Aerosol Independent Clouds being concentrated in late afternoons. A tiny increase in ADC occurs and dominates the cloud cover variation at night and in the first hours of the day in the POLLUTED run compared to the PRISTINE one. This generates a small near surface temperature reduction that lasts until midday, slightly inhibiting convection and limiting its occurrence in the afternoon. The effect is to reduce the development of AIC (and of precipitation) and thus increase solar radiation at the ground: the negative temperature anomaly weakens in the high altitudes and it becomes positive in lowlands from late afternoon trough the night. This mechanism of suppression of convective clouds by aerosols due to the stabilization of the air column has been already studied over Southern China (Zhang et al., 2020), and it is also in agreement with the findings of Van Den Heever and Cotton 2007 and Da Silva et al. 2018. At high altitudes clouds are more frequent, as they form when the winds are diverted upwards along the slopes of the mountains. Those orographic clouds are ADC. They are more frequent in POLLUTED and induce a strong cooling of the near surface air by filtering shortwave radiation. The negative anomaly in temperature is very strong and persists over the night. Even at high elevation this cooling reduces the occurrence of convection, and limits the number of convective cloud events. Averaged over the whole day, however, there is an increase of cloud cover as the change in ADC dominates over that of AIC.

The interpretation of the results in this study has been done without any attempt to separate the effect of aerosols as cloud condensation nuclei and as ice nuclei. It is known that the effects of CCN and IN on clouds and precipitations can be very different: while it is generally thought that in warm clouds the increase in particulate increases the cloud lifetime and delays the onset of precipitation (e.g. Albrecht, 1989; Christensen et al., 2020), studies on mixed phase clouds indicate that the increase in ice nuclei could result in earlier and stronger precipitation (Zeng et al., 2009b, a; Deng et al., 2018; Yang et al., 2020). Further studies varying the concentration of CCN and IN separately in this region of complex orography will shed light on their relative role in cloud formation, duration, and precipitation. The results could also depend on the size of CCN, a topic that has not been investigated in this study: Van Den Heever and Cotton 2007 showed that while larger loads of CCN can reduce precipitation, giant $\mathrm{CCN}$ can actually increase it. 
https://doi.org/10.5194/acp-2021-921

Preprint. Discussion started: 15 November 2021

(C) Author(s) 2021. CC BY 4.0 License.

(c) (P)
Atmospheric

Chemistry

and Physics

Discussions

It should also be noted that the set up of our numerical experiments does not allow to properly account for small scale processes, such as turbulent mixing. For instance, the evaporation-entrainment feedback is a process that has been described to occur on the edge of non-precipitating cumulus clouds and that can favor the evaporation of droplets (Jiang et al., 2006; Small et al., 2009).

The design of this study purposely overlooked aerosol direct and semi-direct effects on radiation, that could modify, even substantially, the climatic response. However, modeling studies of this kind allow us to separately consider each effect and understand it. Further work will be needed to analyze other aerosol effects on climate and to determine whether the total effect, through all the different processes, is merely a linear sum of each of them or not.

Data availability. The datasets generated and analysed during the current study are available from the authors on reasonable request.

Author contributions. A.N., A.P. and C.P designed the experiments; A.N. performed the simulations; A.N. performed the analysis and prepared the figures with the help of F.D.; C.P. conceived the project; A.N., F.D. and C.P. wrote the paper; all authors interpreted the results.

215 Competing interests. The authors declare that they have no conflict of interest.

Acknowledgements. The authors would like to thank Gregory Thompson at NCAR for helping to use the Thompson aerosol-aware scheme. Thanks are due to LRZ Supercomputing Centre, Garching, Germany, SuperMUC Petascale System, project-ID: pr62ve and CINECA Italian computing centre, Bologna, Italy, MARCONI Tier-0 supercomputer, project-ID: mBI20_AmbCo where the numerical simulations were performed and analyzed. This work is an outcome of Project MIUR - Dipartimenti di Eccellenza 2018-2022. The authors acknowledge support from the project JPI Climate Oceans EUREC4A-OA. FD is supported by HPC-TRES grant number 2020-10. 


\section{References}

Albrecht, B. A.: Aerosols, cloud microphysics, and fractional cloudiness, Science, 245, 1227-1230, 1989.

Alizadeh-Choobari, O.: Impact of aerosol number concentration on precipitation under different precipitation rates, Meteorological Applications, 25, 596-605, 2018.

Alizadeh-Choobari, O. and Gharaylou, M.: Aerosol impacts on radiative and microphysical properties of clouds and precipitation formation, Atmospheric Research, 185, 53-64, 2017.

Christensen, M. W., Jones, W. K., and Stier, P.: Aerosols enhance cloud lifetime and brightness along the stratus-to-cumulus transition, Proceedings of the National Academy of Sciences, 117, 17 591-17 598, 2020.

Da Silva, N., Mailler, S., and Drobinski, P.: Aerosol indirect effects on summer precipitation in a regional climate model for the EuroMediterranean region, in: Annales Geophysicae, vol. 36, pp. 321-335, 2018.

Davini, P., Hardenberg, J. v., Corti, S., Christensen, H. M., Juricke, S., Subramanian, A., Watson, P. A., Weisheimer, A., and Palmer, T. N.: Climate SPHINX: evaluating the impact of resolution and stochastic physics parameterisations in the EC-Earth global climate model, Geoscientific Model Development, 10, 1383-1402, 2017.

Deng, X., Xue, H., and Meng, Z.: The effect of ice nuclei on a deep convective cloud in South China, Atmospheric Research, 206, 1-12, 2018.

Fiori, E., Comellas, A., Molini, L., Rebora, N., Siccardi, F., Gochis, D., Tanelli, S., and Parodi, A.: Analysis and hindcast simulations of an extreme rainfall event in the Mediterranean area: The Genoa 2011 case, Atmospheric Research, 138, 13-29, 2014.

Hansen, J., Sato, M., and Ruedy, R.: Radiative forcing and climate response, Journal of Geophysical Research: Atmospheres, 102, 6831$6864,1997$.

240 Haywood, J. and Shine, K.: The effect of anthropogenic sulfate and soot aerosol on the clear sky planetary radiation budget, Geophysical Research Letters, 22, 603-606, 1995.

Hong, S.-Y., Noh, Y., and Dudhia, J.: A new vertical diffusion package with an explicit treatment of entrainment processes, Monthly weather review, 134, 2318-2341, 2006.

Iacono, M. J., Delamere, J. S., Mlawer, E. J., Shephard, M. W., Clough, S. A., and Collins, W. D.: Radiative forcing by long-lived greenhouse gases: Calculations with the AER radiative transfer models, Journal of Geophysical Research: Atmospheres, $113,2008$.

Jiang, H., Xue, H., Teller, A., Feingold, G., and Levin, Z.: Aerosol effects on the lifetime of shallow cumulus, Geophysical Research Letters, $33,2006$.

Li, Z., Niu, F., Fan, J., Liu, Y., Rosenfeld, D., and Ding, Y.: Long-term impacts of aerosols on the vertical development of clouds and precipitation, Nature Geoscience, 4, 888-894, 2011.

Ochoa, C. A., Quintanar, A. I., Raga, G. B., and Baumgardner, D.: Changes in intense precipitation events in Mexico City, Journal of Hydrometeorology, 16, 1804-1820, 2015.

Pavlidis, V., Katragkou, E., Prein, A., Georgoulias, A. K., Kartsios, S., Zanis, P., and Karacostas, T.: Investigating the sensitivity to resolving aerosol interactions in downscaling regional model experiments with WRFv3. 8.1 over Europe, Geoscientific Model Development, 13, 2511-2532, 2020.

Penner, J. E., Andreae, M., Annegarn, H., Barrie, L., Feichter, J., Hegg, D., Jayaraman, A., Leaitch, R., Murphy, D., Nganga, J., et al.: Aerosols, their direct and indirect effects, in: Climate Change 2001: The Scientific Basis. Contribution of Working Group I to the Third Assessment Report of the Intergovernmental Panel on Climate Change, pp. 289-348, Cambridge University Press, 2001. 
Pepin, N., Bradley, R. S., Diaz, H., Baraër, M., Caceres, E., Forsythe, N., Fowler, H., Greenwood, G., Hashmi, M., Liu, X., et al.: Elevationdependent warming in mountain regions of the world, Nature climate change, 5, 424-430, 2015.

Qian, Y., Gong, D., Fan, J., Leung, L. R., Bennartz, R., Chen, D., and Wang, W.: Heavy pollution suppresses light rain in China: Observations and modeling, Journal of Geophysical Research: Atmospheres, 114, 2009.

Ramanathan, V., Crutzen, P., Kiehl, J., and Rosenfeld, D.: Aerosols, climate, and the hydrological cycle, science, 294, $2119-2124,2001$.

Rangwala, I., Miller, J. R., Russell, G. L., and Xu, M.: Using a global climate model to evaluate the influences of water vapor, snow cover and atmospheric aerosol on warming in the Tibetan Plateau during the twenty-first century, Climate Dynamics, 34, 859-872, 2010.

Rosenfeld, D., Lohmann, U., Raga, G. B., O’Dowd, C. D., Kulmala, M., Fuzzi, S., Reissell, A., and Andreae, M. O.: Flood or drought: How do aerosols affect precipitation?, science, 321, 1309-1313, 2008.

Sandrini, S., Fuzzi, S., Piazzalunga, A., Prati, P., Bonasoni, P., Cavalli, F., Bove, M. C., Calvello, M., Cappelletti, D., Colombi, C., et al.: Spatial and seasonal variability of carbonaceous aerosol across Italy, Atmospheric Environment, 99, 587-598, 2014.

Schroeder, P., Belis, C., Schnelle-Kreis, J., Herzig, R., Prévôt, A. S., Raveton, M., Kirchner, M., and Catinon, M.: Why air quality in the Alps remains a matter of concern. The impact of organic pollutants in the alpine area, Environmental Science and Pollution Research, 21, 252-267, 2014.

Small, J. D., Chuang, P. Y., Feingold, G., and Jiang, H.: Can aerosol decrease cloud lifetime?, Geophysical Research Letters, $36,2009$.

Stjern, C. W., Samset, B. H., Boucher, O., Iversen, T., Lamarque, J.-F., Myhre, G., Shindell, D., and Takemura, T.: How aerosols and greenhouse gases influence the diurnal temperature range, Atmospheric Chemistry and Physics, 20, 13 467-13 480, 2020.

Tao, W.-K., Chen, J.-P., Li, Z., Wang, C., and Zhang, C.: Impact of aerosols on convective clouds and precipitation, Reviews of Geophysics, $50,2012$.

Thompson, G. and Eidhammer, T.: A study of aerosol impacts on clouds and precipitation development in a large winter cyclone, Journal of the atmospheric sciences, 71, 3636-3658, 2014.

Tiedtke, M.: A comprehensive mass flux scheme for cumulus parameterization in large-scale models, Monthly weather review, 117, 1779$1800,1989$.

Van Den Heever, S. C. and Cotton, W. R.: Urban aerosol impacts on downwind convective storms, Journal of Applied Meteorology and Climatology, 46, 828-850, 2007.

Yang, Y., Sun, J., Zhu, Y., and Zhang, T.: Examination of the impacts of ice nuclei aerosol particles on microphysics, precipitation and electrification in a 1.5D aerosol-cloud bin model, Journal of Aerosol Science, 140, 105440, https://doi.org/https://doi.org/10.1016/j.jaerosci.2019.105440, 2020.

Zeng, X., Tao, W.-K., Zhang, M., Hou, A. Y., Xie, S., Lang, S., Li, X., Starr, D. O., and Li, X.: A contribution by ice nuclei to global warming, Quarterly Journal of the Royal Meteorological Society: A journal of the atmospheric sciences, applied meteorology and physical oceanography, 135, 1614-1629, 2009a.

Zeng, X., Tao, W.-K., Zhang, M., Hou, A. Y., Xie, S., Lang, S., Li, X., Starr, D. O., Li, X., and Simpson, J.: An indirect effect of ice nuclei on atmospheric radiation, Journal of the atmospheric sciences, 66, 41-61, 2009b.

Zhang, L., Fu, T.-M., Tian, H., Ma, Y., Chen, J.-P., Tsai, T.-C., Tsai, I.-C., Meng, Z., and Yang, X.: Anthropogenic Aerosols Significantly Reduce Mesoscale Convective System Occurrences and Precipitation Over Southern China in April, Geophysical Research Letters, 47, e2019GL086 204, 2020. 
https://doi.org/10.5194/acp-2021-921

Preprint. Discussion started: 15 November 2021

(c) Author(s) 2021. CC BY 4.0 License.

(c) (i)

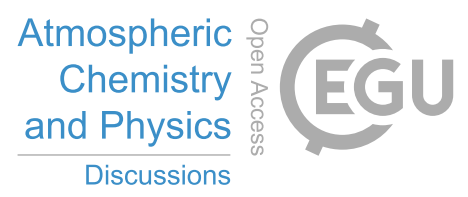

Zhang, S., Wang, M., Ghan, S. J., Ding, A., Wang, H., Zhang, K., Neubauer, D., Lohmann, U., Ferrachat, S., Takeamura, T., et al.: On the characteristics of aerosol indirect effect based on dynamic regimes in global climate models, Atmospheric Chemistry and Physics, 16, 2765-2783, 2016. 